\title{
Tuberculosis in Ethiopian prisons
}

Citation for published version (APA):

Asmare, K. (2018). Tuberculosis in Ethiopian prisons: epidemiology, risk factors and best practices for improving the case detection. [Doctoral Thesis, Maastricht University]. Datawyse / Universitaire Pers Maastricht. https://doi.org/10.26481/dis.20181024ak

Document status and date:

Published: 01/01/2018

DOI:

10.26481/dis.20181024ak

Document Version:

Publisher's PDF, also known as Version of record

\section{Please check the document version of this publication:}

- A submitted manuscript is the version of the article upon submission and before peer-review. There can be important differences between the submitted version and the official published version of record.

People interested in the research are advised to contact the author for the final version of the publication, or visit the DOI to the publisher's website.

- The final author version and the galley proof are versions of the publication after peer review.

- The final published version features the final layout of the paper including the volume, issue and page numbers.

Link to publication

\footnotetext{
General rights rights.

- You may freely distribute the URL identifying the publication in the public portal. please follow below link for the End User Agreement:

www.umlib.nl/taverne-license

Take down policy

If you believe that this document breaches copyright please contact us at:

repository@maastrichtuniversity.nl

providing details and we will investigate your claim.
}

Copyright and moral rights for the publications made accessible in the public portal are retained by the authors and/or other copyright owners and it is a condition of accessing publications that users recognise and abide by the legal requirements associated with these

- Users may download and print one copy of any publication from the public portal for the purpose of private study or research.

- You may not further distribute the material or use it for any profit-making activity or commercial gain

If the publication is distributed under the terms of Article $25 \mathrm{fa}$ of the Dutch Copyright Act, indicated by the "Taverne" license above, 
Summary 
The studies presented in this thesis defined the burden of TB and factors driving TB in Ethiopian prisons and explored a potentially feasible intervention model for TB control in resource-limited prison settings.

Chapter 1 regards the results of relevant literature upon which we structured our research questions. It describes the existing challenges facing the global TB control program and justifies the rationale for the planned investigations.

Despite the huge progress on its control, TB remains a global public health concern. With an estimated 10.4 million incident cases worldwide and 1.4 million deaths each year, TB still takes a huge death toll, particularly in Africa. Ethiopia remains one of the 30 world's high TB/MDR-TB burden countries where more than 26,000 TB fatalities occur every year. The majority of the TB cases and fatalities occur among the most productive age groups, imposing a significant economic burden and impeding the country's progress toward middle-income status.

Missed or delayed diagnoses and poor access to the high-quality care represent major obstacles to the global TB control program. Each year an estimated three million individuals with active TB do not receive a diagnosis and remain a source of onward transmission of the disease, particularly in low- and middle-income countries. Overlooking high-risk populations such as prisoners from control programs is a major factor for these failures. This is particularly important for prisons in Sub-Saharan Africa, including Ethiopian prisons, where HIV infection and poverty are prevalent, and the internationally recommended TB control guidelines (early case detection and treatment, prompt isolation of contagious inmates, etc.) are not under practice. The lack of resources and organized health systems in prisons of these countries limits the implementation such guidelines. On the other hand, accurate data required to develop optimized and potentially feasible interventions, to tackle the ominous problem of TB in prisons of such countries, are scanty and unreliable.

Considering these gaps, we centered this thesis on the following four principal objectives. First, we investigated the prevalence and factors associated with undiagnosed TB among prisoners. Second, we determined the treatment success rate (TSR) of prisoners with TB and assessed the risk factors for unsuccessful outcome. Third, we assessed the knowledge, attitudes, and practices (KAP) of prisoners about TB. Fourth, based on the findings of these studies, we designed and executed an intervention to tackle the problem of poor knowledge and a high burden of undiagnosed TB in prisons.

The study investigating the prevalence of undiagnosed TB is presented in Chapter 2. In total, 9299 prisoners were screened for TB symptoms using a standardized symptombased questionnaire in nine prisons of Tigray. Sputum samples were collected from 844 symptomatic patients and direct microscopy and culture were done for TB diagnosis. HIV testing was conducted using rapid test kits. Moreover, data on sociodemographic and general health status of the participants were collected using a structured questionnaire. 
Our findings show that the prevalence of undiagnosed TB was high among prisoners in Tigray. Out of 809 presumptive TB cases with culture result, $4.0 \%$ were confirmed to have undiagnosed TB. The overall estimated point prevalence of undiagnosed TB was $505 / 100,000$ prisoners. In addition, $4.4 \%$ (36/809) the presumptive TB cases, and $6.3 \%$ $(2 / 32)$ undiagnosed TB cases were infected with HIV. Chewing Khat $(O R=2.81)$, and having had a close contact with a TB patient $(O R=2.18)$ were found to be predictors of undiagnosed TB among presumptive TB cases.

The prevalence found in this study is more than two folds higher than the estimated prevalence of undiagnosed TB in the general population of Tigray $(216 / 100,000$ population). This is a serious problem because undiagnosed patients would become a source of continual transmission to their fellow prisoners, and potentially to the general population through visitors, prison staff and discharged prisoners. In conclusion, much effort is needed to improve TB case detection in the study prisons.

Chapter 3 presents the results of a retrospective analysis on the treatment outcome of TB cases and risk factors for unsuccessful outcome in northern Ethiopian prisons. In this study, the profile and treatment outcomes of all prisoners diagnosed with TB between September 2010 and August 2015 was retrieved from the TB treatment follow-up clinics of the four selected prisons. Patients' information such as age, sex, the type of TB case, the treatment category, the date of treatment initiation and completion, weight at the time of treatment initiation, HIV status, and other related data were recorded using a standardized recording format.

Our analysis has shown a high rate of treatment success (94\%) for the prisoners that initiate and complete treatment while in the same prison. Briefly, out of the 496 patients, $11.5 \%$ was cured, $68 \%$ completed treatment, $2.5 \%$ was lost to follow-up, $1.6 \%$ was with a treatment failure, $1.4 \%$ died, and $15 \%$ was transferred out. Surprisingly, none transferred out or released prisoners were appropriately linked to health facilities. The odds of unsuccessful outcome was 4.68 times greater among re-treatment cases compared to the newly treated cases. The year of treatment was also associated with variations in TSR; those treated during the earlier year were more likely to have an unsuccessful outcome. Sputum non-conversion at the second-month check-up was strongly associated with unsuccessful outcome among the smear-positive cases.

While the high rate of treatment success in the study prisons is encouraging, the lack of linkage and tracking systems for those prisoners transferred or released before their treatment completion will have a negative implication for the national TB control program as such patients might interrupt their treatment and develop drug-resistant TB. The national TB control program (NTP) and the prison authorities should, therefore, take immediate initiatives in establishing strategies that tackle this problem.

In chapter 4, we described the findings of the KAP survey. Data on the socio-demographic characteristics, prison history, and KAP measures were collected from 615 northern Ethi- 
opian prisoners using a semi-structured standardized questionnaire. The outcome variables were defined considering selected items (so-called basic elements) about TB. Accordingly, levels of KAP were dichotomized and categorized as 'good' knowledge vs. 'poor' knowledge, 'favorable' attitude vs. 'unfavorable' attitude, and 'good' practice vs. 'poor' practice.

Our findings suggest gaps in knowledge, attitudes, and practices with regard to TB among the participating prisoners. Only about four out of ten prisoners were able to recognize germ/bacteria as a cause of TB. The majority related it mainly either to exposure to cold wind, spoiled soil (a soil with a bad odor), poor hygiene, or smoking. In addition, $63.7 \%$ was not aware of the possibility of getting MDR strains due to treatment non-adherence. Overall, only $24 \%$ knew the basic elements about TB, $41 \%$ had favorable attitudes, and a bit more than a half (55\%) had a good practice towards TB. Prisoners who were urban residents were generally more knowledgeable than rural residents $(O R=$ 2.16). Illiterates were found to be less knowledgeable $(O R=0.17)$, less likely to have a favorable attitude $(O R=0.31)$, and a less good practice $(O R=0.35)$. Significant differences were also observed between the different study prisons.

The identified misconceptions should be targeted, as they would contribute to treatment delay and spreading of the disease. Particularly, the misconception of cold wind, locally known as 'nefas/bird', could affect care-seeking behavior and fuel the spread of TB in the overcrowded Ethiopian prisons. This urges the need to design and implement appropriate and sustainable educational intervention models in the prison settings across the country.

Based on the results of the above-mentioned studies, we conducted a clusterrandomized trial to assess the impact of trained inmate peer educators on improving TB case detection, treatment success rate, and reducing pre-treatment symptom duration in northern Ethiopian prisons. This study is described in chapter 5 . Sixteen prisons in the two regions of Ethiopia (with a total population of 18,032) were first matched into pairs. Randomization was then done within matched pairs in which eight prisons from each pair were assigned to the intervention and the remaining ones to the control group. From each intervention prison, prisoners were selected and trained for three days about TB. The trained prisoners (inmate peer educators) then provided health education about TB every two weeks on a regular basis for one year and undertook routine symptom-based TB screening for a referral. The primary outcome measure was the case detection rate at the end of the one year intervention period. In the control prisons, cases were detected within the existing passive case finding approach.

During the one-year study period, 75 and 25 pulmonary TB cases were detected in the intervention and control groups, respectively. The mean case detection rate was higher in the intervention prisons than in the control prisons (79.8\% vs. $26.9 \%)$. It was also possible to shorten the pre-treatment symptom duration by 8.6 days on average, though this difference was not statistically significant. In addition, the overall TB 
knowledge $(O R=2.54)$ and practice $(O R=1.84)$ levels were significantly improved in the intervention prisons. We did not find a significant difference in the treatment success rate but it was high for both groups.

The findings of this trial demonstrate that empowering and involving prisoners in TB control is highly effective in increasing TB case detection rate and reducing misconceptions about TB in the study prisons. This intervention could be scaled-up in other Ethiopian prisons and adapted in other prisons in resource-limited countries with a high TB burden. However, several setting specific issues should be taken into account when considering implementation in other settings. A prison system that faces a high level of violence and distrust among prisoners, would probably not be good for implementing an intervention like ours. Moreover, as peer educators may not always be volunteers, the long-term cost of training and supervising the inmate peer educators should be investigated for large-scale and sustainable implementations.

In the final chapter of this thesis, chapter 6, we present the key findings, methodological considerations, strength and limitations, and conclusions of the studies presented in this thesis. In general, the prevalence of undiagnosed TB was high in the study prisons and misconceptions about the cause of TB and consequences of non-adherence to TB treatment were prevailing among the prisoners. There was also a lack of linkage and tracking systems for prisoners transferred or released before treatment completion. These findings pose serious public health implications and threaten national TB control efforts, with the risk of TB and drug-resistant TB spread in prisons and the general population. We explored that empowering and involving prisoners in TB control program improves TB case finding (detecting of the undiagnosed TB) and reduce misconceptions. The NTP should put more efforts in scaling-up of such intervention model to all prisons in Ethiopia and in transforming the health care system in the prisons. 
